\title{
Autonomia na unidade de terapia intensiva: comecemos por cuidar de nós
}

\author{
Autonomy in intensive care unit: let us start by caring ourselves \\ Autonomía en la unidad de cuidados intensivos: comencemos por cuidar de nosotros mismos
}

\author{
Ambrosina Oliveira Vargas', Flávia Regina Souza Ramos" \\ 'Universidade do Vale dos Sinos. Curso de Enfermagem. São Leopoldo, RS \\ "Universidade Federal de Santa Catarina. Grupo Praxis. Florianópolis, SC
}

Submissão: 19/08/2009

Aprovação: 08/06/2010

\section{RESUMO}

Investigação Qualitativa, balizada na analítica foucaultiana com aproximações no referencial teórico pós-estruturalista, explora a Questão da autonomia como uma das tensões no fazer/saber enfermagem Que pode ser discursivamente articulada à bioética e à tecnobiomedicina. Nesta perspectiva, dos múltiplos vieses Que poderiam emergir ao se fazer uma leitura crítica dos textos analisados (artigos produzidos por enfermeiras) e das entrevistas com os/as enfermeiros/as intensivistas, o tema da autonomia foi analiticamente explorado a partir do conceito de cuidado de si, desdobrando-se em categorias Que expressaram o privilegiamento: da moral como obediência à Lei; da conduta e da moral sobre o conhecimento técnico; e da governabilidade de si no confronto com a técnica. Estas se configuraram como possibilidades éticas do sujeito enfermeira/o intensivista, não como etapas seQuenciais ou concorrentes, mas coligadas e confluentes na experiência do atual momento histórico.

Descritores: Unidade de terapia intensiva; Bioética; Ética.

\section{ABSTRACT}

This study, a Qualitative investigation anchored in Foucaltian analysis with approximations to post-structuralist theory, explores the Question of autonomy as one of the tensions of nursing performance/knowledge which can be discursively articulated to bioethics and to techno biomedicine. From such perspective, from the multiples vies that may emerge to completing a critical reading of the analyzed texts (articles produced by nurses) and of the interviews with intensive care nurses, the theme of autonomy was analytically explored from the concept of self care, unfolding itself into categories which express privileging: morals as obedience to the Law; conduct and morals concerning technical knowledge; self-governing in its confront with technique. These are configured as ethical possibilities for the intensive care nurse/subject, not as sequential or competitive stages, but connected and confluent in the experience of the current historical period.

Key words: Intensive care units; Bioethics; Ethics.

\section{RESUMEN}

Investigación de carácter cualitativo, basada en el análisis foucaultiano con aproximaciones al referencial teórico posestructuralista, en la cual se explora la cuestión de la autonomía como una de las tensiones existentes en el Quehacer/saber enfermería Que pueden ser articuladas discursivamente a la bioética y a la tecnobiomedicina. Desde esa perspectiva, y a partir de las múltiples visiones Que surgieron al hacer una lectura crítica de los textos analizados (artículos producidos por enfermeras) y de las entrevistas realizadas con los enfermeros y las enfermeras intensivistas, el tema de la autonomía fue explorado analíticamente a partir del concepto del cuidado de sí, el cual se desdobló en una serie de categorías Que expresaron el privilegio: de la moral como obediencia a la ley; de la conducta y de la moral sobre el conocimiento técnico; y de la gobernabilidad de sí en la confrontación con la técnica. Esas categorías se configuran como posibilidades éticas del sujeto enfermera/enfermero intensivista, no como etapas secuenciales o concurrentes, sino como correlativas y confluentes en la experiencia del actual momento histórico.

Descriptores: Unidades de terapia intensiva; Bioética; Ética.

\section{AUTOR CORRESPONDENTE Ambrosina Oliveira Vargas. Av. Protásio Alves, 7I57. CEP 9I3 I0-003. Porto Alegre, RS. \\ E-mail: maraav@terra.com.br}




\section{INTRODUÇÃO}

Quem somos nós, enfermeiras, profissionais de saúde, neste momento da história ${ }^{(1)}$ Essa pergunta é inspirada, principalmente, na releitura de Foucault do texto kantiano que aborda a autonomia. E, a partir dessa pergunta, o presente artigo desencadeia uma análise Que, entre outros aspectos, sinaliza a contradição entre uma formação Que busca, essencialmente, a competência técnica das enfermeiras, Que as prepare para atuar junto aos clientes, e a constatação da não-competência política das enfermeiras, concretizada no processo de acomodação em muitas situações práticas, das Quais a enfermeira participa, em Que o sujeito enfermeira se vê desrespeitado na sua autonomia e permite desrespeitar-se, por diferentes formas. Ainda, argumenta em favor da necessidade das enfermeiras transformarem suas práticas em correspondentes a uma vontade, racionalmente considerada como boa em si mesma. Portanto, uma vontade boa por si própria, Que não decorreria da vontade de outrem e que ultrapassaria a lógica das normas explícitas e implícitas, dos diferentes códigos, das determinações prescritivas e das ordens inquestionáveis ${ }^{(1)}$.

Por sua vez, reportando-nos, diretamente, às argumentações de Foucault ao texto kantiano, encontramos o pressuposto de Que para o sujeito sair da minoridade e alcançar a maturidade são exigidas a coragem e a decisão em promover um trabalho sobre si mesmo: uma atitude. A atitude nova a ser tomada é aquela pertinente à própria atualidade, e a decisão mais relevante na atualidade refere-se ao estilo de vida de cada um, ao modo pelo Qual nos tornamos artífices de nosso próprio ethos. No entanto, essa releitura do texto kantiano por Foucault implica, em primeiro lugar, o abandono das condições transcendentais, para pensá-las como históricas e contingentes. Ou seja, o conhecimento e a ação encontram suas condições de desenvolvimento dentro de certas epistémes e de certos espaços de saber e poder. Em segundo lugar, ser artífice do próprio ethos significa abandonar os fundamentos para substituí-los pela experiência, já Que nenhuma orientação normativa ou essencializada do sujeito sustenta o ethos, a não ser seu próprio acontecimento histórico. Assim, a busca da autonomia e liberdade não se realiza mais num movimento de verticalidade, de busca do eu profundo, da superação da ambivalência em busca do eu verdadeiro. O sujeito, nesse modelo, não seria nem livre nem emancipado, mas submetido a um processo de disciplinamento social, uniformizado pelo constrangimento. O cuidado de si e a criação de um estilo de vida dissolvem os determinismos e abrem um espaço de possibilidade adequado às novas exigências da pluralidade, pois podemos constituirmo-nos como sujeitos em função da multiplicidade de experiências ${ }^{(2)}$.

Assim, Foucault insere a prerrogativa de que é o cuidado de si o Que tem de entrar primeiro na pauta da discussão, antes mesmo de pensarmos em cuidar dos outros. Um cuidado de si que deve, por ele mesmo e a título de consequência, produzir, induzir as condutas pelas Quais poderemos efetivamente passar a cuidar dos outros. Logo, balizadas na expressão comecemos por cuidar de nós, alavancamos, neste artigo, uma analítica foucaultiana com aproximações no referencial teórico pós-estruturalista, buscando explorar a Questão da autonomia como uma das tensões no fazer/ saber enfermagem Que pode ser discursivamente articulada à bioética.

\section{MÉTODO}

O estudo Qualitativo utilizou fontes documentais e de entrevistas com enfermeiros/as intensivistas. O corpus documental foi composto por artigos publicados pela enfermagem brasileira, no período de 1984 a 2007, pois um estudo ${ }^{(4)}$ aponta 1984 como o ano em Que a Revista Brasileira de Enfermagem (REBEn) publicou o primeiro artigo Que contemplou a temática bioética. Incluímos, como artigos a serem investigados, os publicados nos periódicos nacionais de enfermagem Que alcançaram, em QualQuer ano entre 2000 e 2007. nota B Internacional pelo sistema Qualis (Revista Latino-Americana de Enfermagem; Revista Acta Paulista; Revista Texto \& Contexto Enfermagem; Revista Escola de Enfermagem USP). Além destas, inserimos a REBEn, por ela configurar-se em um emblemático periódico para a Enfermagem brasileira, e a Revista O Mundo da Saúde, cientes de que muitos/as enfermeiros/as publicam em periódicos específicos de bioética. Delimitamos, nos respectivos periódicos, 113 artigos, através de uma busca manual, minuciosa e mais abrangente, procurando temáticas e assuntos que poderiam enriQuecer a discussão acerca das Questões da bioética e da terapia intensiva. Assim, além de orientarmos a busca pelos descritores bioética e UTI e enfermagem, ética e UTI, bioética e enfermagem, ampliamos, pois apesar de artigos não referenciarem, explicitamente, o termo bioética, os assuntos abordados reproduziam temas relacionados com a bioética. Em outros momentos, achávamos temas articulados à ética de modo indiferenciado aos articulados à bioética. Enfim, a partir dos 113 artigos, selecionamos 17 artigos Que nos direcionaram para abordar a Questão da autonomia do/a enfermeiro/ a no contexto da terapia intensiva.

Além da análise dos 17 artigos selecionados, entrevistamos 20 enfermeiros/as inseridos/as no contexto da terapia intensiva, na denominada Região Metropolitana de Porto Alegre, no estado do Rio Grande do Sul, utilizando o critério de saturação de dados. Após aprovação do projeto em Comitê de Ética (Parecer n ${ }^{\circ}$ 186/ 07/CEP/UFSC), os sujeitos foram convidados/as a participar do estudo e manifestaram seu aceite por meio do Termo de Consentimento Livre e Esclarecido, conforme Resolução 196/96.

\section{RESULTADOS E DISCUSSÃO}

\section{Possibilidade ética do sujeito}

"Penso Que há aí a possibilidade de elaborar uma história daquilo Que fizemos e Que seja ao mesmo tempo uma análise daquilo Que somos; uma análise teórica Que tenha um sentido político - Quero dizer, uma análise Que tenha um sentido para o Que Queremos aceitar, recusar, mudar de nós mesmos em nossa atualidade. Tratase, em suma, de partir em busca de uma outra filosofia crítica: uma filosofia Que não determina as condições e os limites de um conhecimento de objeto, mas as condições e as possibilidades indefinidas de transformação do sujeito"(3).

$\mathrm{Na}$ diferenciação entre os termos moral e ética, nessa busca de construção de novas formas de subjetividade, Foucault utiliza o termo moral como "valores e regras de ação propostas aos indivíduos e aos grupos por intermédio de aparelhos prescritivos diversos", e o termo ética como "elaboração do trabalho ético que se efetua sobre si mesmo, não somente para tornar seu próprio comportamento conforme uma regra dada, mas também para tentar 
se transformar a si mesmo em sujeito moral de sua própria conduta”(5) . Na direção desse entendimento foucaultiano de ética, um dos artigos analisados considera que falar da ética de obediência, da ética benthaniana, da ética utilitarista ou até da ética cristã "presentes na enfermagem, assemelhar-se-ia a falar de uma nãoética pela presença de relação de dependência a outrem, a alguém fora de si, pela perda de autonomia do sujeito"(6).

Mesmo concordando com essa assertiva, tensionamos um pouco a expressão assemelhar-se-ia a falar de uma não-ética. Quando Foucault trata da possibilidade ética do sujeito, evoca de imediato a análise crítica da história do Que fizemos e do Que somos para, a partir daí, sim, aceitar, recusar ou mudarmos a nós mesmos em nossa atualidade. Ou seja, em Foucault, as identidades se constituem e se desfazem na contingência, na precariedade, na determinação histórica. Assim, o filósofo, ao descrever o sujeito em sua dimensão ética, retoma a propósito desse sujeito o Que havia enunciado Quanto ao poder, ou seja: da mesma forma como o poder não deveria ser pensado como lei, "mas como estratégia, sendo a lei apenas uma possibilidade estratégica entre outras", "a moral como obediência à Lei é apenas uma possibilidade ética entre outras;" por sua vez, "o sujeito moral é apenas uma realização histórica do sujeito ético"(3). A partir desse referente, poderíamos dizer Que a ética da obediência, a ética benthaniana, a ética utilitarista e a ética cristã, presentes na enfermagem, constituem-se, ao seu modo e no seu tempo, em algumas das possibilidades éticas do sujeito enfermeiro/a.

De outra maneira, distantes das constituições transcendentais, uma possibilidade ética da enfermagem (como as identificadas acima) é prática de si; como a ponta de lança de uma idéia de sujeito historicamente referenciável, claro Que, também, em composição com técnicas de dominação, também elas historicamente datáveis. "De resto, o indivíduo-sujeito emerge tão-somente no cruzamento entre uma técnica de dominação e uma técnica de si. Ele é a dobra dos processos de subjetivação sobre os procedimentos de sujeição, [...] ao sabor da história, Que mais ou menos se recobrem"(3).

Nessa perspectiva, com relação à autonomia, dos múltiplos aspectos e Questões Que poderiam emergir ao se fazer uma leitura crítica dos textos analisados e das entrevistas com os/as enfermeiros/as, salientamos aQueles mais diretamente ligados ao privilegiamento da moral como obediência à Lei; da conduta e da moral sobre o conhecimento técnico; e da governabilidade de si no confronto com a técnica. Assim sendo, dividimos a nossa análise da possibilidade ética do sujeito enfermeira/o intensivista em três etapas. Etapas Que não são cronológicas ou seQuenciais; na verdade são, ainda, concomitantes, algumas vezes concorrentes, em muitos momentos, coligadas.

\section{Possibilidade Ética I: a moral como obediência à Lei}

Nas leituras e releituras dos artigos, encontramos um conjunto destes, pertinentemente datados entre 1985 e 1995, Que discutem tanto o Decreto Lei do Exercício Profissional da Enfermagem, número 94.406 de 08.06.87, como os Códigos de Ética de 1958, 1975 e de 1993. Assim, enfatizamos, aQui, algumas das Questões discutidas nesses artigos.

Uma primeira Questão abordada é o estabelecimento, no Decreto Lei do Exercício Profissional de Enfermagem, das competências privativas do enfermeiro, considerando a consulta e prescrição da assistência de enfermagem e os cuidados de enfermagem diretos a pacientes graves com risco de vida e os de maior complexidade técnica e que exijam conhecimentos adequados e capacidade de tomar decisões imediatas, inexistentes na legislação anterior ${ }^{(7)}$. Atrelamos essa Questão com a fala abaixo:

Sou enfermeira de UTI desde 1985, ano em Que os hospitais passaram a contratar enfermeiras para este setor. Era uma enfermeira para toda a UTI e a mesma representava todos os turnos. Depois passou a ter enfermeiros em todos os turnos. Mais adiante, ficava uma enfermeira para cada 10 pacientes. Hoje, há hospitais em Porto Alegre com uma enfermeira para cada quatro a cinco leitos. Sei que, em São Paulo, existem hospitais em que o dimensionamento é um enfermeiro para cada leito ou, no máximo, dois leitos. (Sujeito 5)

Mesmo que a referida Lei se dirija para QualQuer setor/unidade Que possa atender pacientes graves e com risco de vida, normalmente é na UTI Que esses sujeitos exigem dos profissionais maior habilidade com o arsenal tecnológico, além de conhecimentos específicos e capacidade de tomar decisões imediatas. No entanto, a fala acima não se reporta a alguma exigência da Lei do Exercício Profissional, nem mesmo ao Regulamento Técnico para Funcionamento de Serviços de Atenção ao Paciente Crítico e Potencialmente Crítico, conforme a Agência Nacional de Vigilância Sanitária. 'Aparentemente' descolada de Qualeuer pressuposto legal, a fala 'apenas' refletiria uma mudança percebida na forma das sociedades responderem a seus problemas.

Ainda com relação a essa primeira Questão, referenciamos outro artigo Que busca problematizar algumas situações polêmicas e os vetos Que incidiram sobre a proposta original da Lei do Exercício Profissional. Um dos contrapontos é, justamente, o das competências privativas do enfermeiro, asseverando que, mais do Que estratificar e hierarQuizar a prática da enfermagem, essa Lei deveria estabelecer parâmetros referenciais das competências, reafirmar o princípio da democratização interna do trabalho para uma adeQuada assistência de enfermagem e ter como preocupação central a garantia das condições externas e determinantes do pleno exercício profissional. Quanto aos vetos, o artigo analisa Que eles mutilam os avanços significativos Que teríamos na Lei, como autonomia, mercado de trabalho, organização profissional, e exemplifica com a justificativa oficial para vetar o artigo 10: é discutível a autonomia na execução dos serviços e da assistência de enfermagem sem a supervisão médica ${ }^{(8)}$. O artigo expressa, claramente, a dificuldade gerada caso se adote uma visão simplista Quanto ao Que importa para obtermos ou não mais autonomia.

O segundo viés para discussão, encontrado em um ensaio reflexivo, trata da "evolução dos princípios morais adotados pela Enfermagem brasileira desde 1923 até os dias atuais". Para tanto, analisa os Códigos de Ética de 1958, 1975 e 1993, assinalando uma tendência metafísica, abstrata e espiritual dos dois primeiros, e uma mudança no Código de 1993, o Qual procura ver os valores de forma histórica e baseados em uma visão de processo ${ }^{(9)}$. Para justificar o encontrado nos dois primeiros códigos, é argumentado Que a ênfase dada pela enfermagem à transmissão e inculcação dos valores morais em seus membros visava criar certa homogeneização das atitudes Que eles deveriam ter como seres humanos e como profissionais. Sua analítica evidencia a noção de Que 'a 'natureza' já havia prestado o seu serviço ao munir as 
enfermeiras de Qualidades morais inatas, desenvolvidas através do estudo da religião". Ou seja, é referendado Que por meio da religião, naQuele período histórico, obter-se-ia uma "boa formação de caráter", através da formação da vontade, do desenvolvimento de ideais dignos, da aQuisição de hábitos corretos e do controle das emoções, enfim, da aQuisição da integridade moral. Inclusive, mesmo Que o excerto abaixo possa nos levar a outras análises produtivas, Queremos demarcar, agora, um possível modo de ser sujeito enfermeira em 1958, atrelado à moral como obediência à Lei:

Visando não deixar Qualeuer ponto obscuro Quanto aos limites e abrangências do desempenho esperado da profissional, o Artigo Oitavo do Código de 1958 sentencia: 'o enfermeiro executa as prescrições médicas com inteligência e lealdade [...]. Somente em situação de extrema urgência, aplica tratamentos médicos sem prescrição, relatando-os ao médico responsável o mais breve possível'. A relação de poder está estabelecida. Claro Que ela não se configura no fato da enfermeira poder ou não prescrever medicamentos, este é um limite Que serve apenas para demarcar espaços profissionais e competências, tão valiosos e corrieueiros no campo científico a partir da modernidade. O ponto crucial está na forma como esses limites são estabelecidos e como o seu cumprimento se dá. Como podemos inferir da letra do código, não existe uma demarcação de saberes entre enfermeiras e médicos, e sim a apresentação de um saber, como único, privativo dos médicos e o cumprimento de tarefas, voltadas para a objetivação desse saber, destinado às enfermeiras ${ }^{(9)}$.

Um terceiro aspecto nos reporta aos deveres profissionais, inferidos, por exemplo, pela linguagem utilizada nos códigos de ética. O mesmo artigo acima pondera Que o Código de 1993 substitui os verbos zelar e cuidar por orientar e colaborar. Para ilustrar essa argumentação, cita o Artigo 3 I do Capítulo III, Quando este determina Que a enfermeira tem, como uma de suas funções, Que colaborar com a equipe de saúde na orientação do cliente ou responsável sobre os riscos dos exames ou de outros procedimentos. Desse modo, em sua análise, a enfermeira deixa de ser apenas uma cumpridora de tarefas e passa a ter uma posição de igualdade com os outros componentes da equipe de saúde. Logo, o fato de poder preparar o paciente sobre a Qualidade do tratamento a Que vai se submeter pressupõe Que ela esteja engajada e tão informada Quanto os demais profissionais, ou seja, Que esteja colocada no mesmo nível deles ${ }^{(9)}$.

Já o Quarto aspecto de Que vamos tratar é explorado por meio de outro artigo. Este relembra a máxima de Que conhecer os princípios normativos que orientam as condutas dos indivíduos, como membros de uma determinada categoria profissional, reQuer não perder de vista a sua relação com as condições em Que foram produzidos, ou seja, com os valores vigorantes na sociedade. A nossa prática profissional é, pois, influenciada por fatores econômicos, políticos e religiosos, entre outros; contudo, a maior influência Que a estética profissional recebe é da própria moral oficial. E, a incursão desses valores gerais nos domínios da ética profissional faz-se de forma 'natural', através de uma ação política sutil. Nesse sentido, o texto segue alegando Que o termo deontológico, usado como sinônimo de "ética profissional", surgiu para definir um tipo de conhecimento Que pretendia orientar os indivíduos a irem ao encontro do prazer; etimologicamente, o termo vem do grego déon - Que Quer dizer o "obrigatório, o justo, o adequado" - ou de déontos, também do grego, que significa "necessidade”. Logo, a praticidade Que envolve os códigos de ética profissional não os exime de um compromisso com os interesses da categoria e com o projeto global da sociedade, fazendo com Que eles movimentem-se a depender das oscilações sociais e, desse modo, seguindo orientações teóricas também diferentes. Se a sociedade é regida por uma orientação metafísica, os códigos de ética profissional tendem a seguir princípios metafísicos; se ela admite que o homem é um microcosmos capaz de construir, transformar e criar, eles tendem a valorizar esses aspectos; se a sociedade segue uma orientação individualista e egoísta, os códigos colocarão em prática esses valores. Sinaliza, por fim, Que os códigos de ética necessitam passar de meras regras de orientação de mercado, para uma prática reflexiva e crítica Que lhes daria o status deontológico ${ }^{(10)}$.

Articulando, agora, os Quatro aspectos enfatizados, chegamos a uma síntese provisória entre: uma Lei Que, entre outros pressupostos, vem buscando restringir o cuidado aos pacientes graves como privativo dos/as enfermeiros/as; os princípios morais e de conduta que vem sendo alternados e alterados, interferindo na elaboração dessa Lei; uma linguagem cambiável na elaboração dos respectivos códigos de ética e, por último, já Que, necessariamente, alguns dos próprios sujeitos profissionais são os Que formulam as regras de conduta, uma manifestação de Que a deontologia e os códigos de ética deveriam ser olhados, por aqueles Que o utilizam, de jeito menos estreito, objetivando, com isso, melhorar o 'jogo' para todos. Portanto, eis os Quatro aspectos enfatizados por nós. Eis a possibilidade ética I: a moral como obediência à Lei. Obediência, então, Que não significa atributo em si ou algo dado e definitivo, mas algo Que interessa e faz sentido em um lugar e tempo, porque remete tanto às exigências práticas Quanto às respostas configuradas em termos de Lei.

Uma moral como obediência à Lei, Que veria apenas o lado dos Que falam e elaboram os textos prescritivos? Poder-se-ia supor Que, por serem textos prescritivos, eram e são recomendações vazias, uma espécie de código sem conteúdo e sem aplicação real? Se assim fosse, esses textos prescritivos jamais se inscreveriam realmente no comportamento e na experiência dos profissionais. Paradoxalmente, a moral, como obediência à Lei, ora está centrada em um problema de escolha do próprio grupo, ora como normativa externa aos interesses da profissão. A Lei está em permanente construção, por pressupor uma relação. Quando a Lei retorna e incide sobre o sujeito, ela já retorna de outro jeito, sob efeito de um deslizamento produzido pela transformação do tempo e das condições de sua instalação primeira. Não seria uma atualização, mas uma reinstalação da Lei. O discurso não constitui um sujeito unilateralmente, mas simultaneamente e, por isso, a mesma norma Que aprisiona traz em si a possibilidade de resistir a ela e transformá-la.

Desse modo, tanto os artigos como a fala nos levam a ressaltar o caráter artificial, complexo e político de como se processam as mudanças nas práticas e o modo com Que estas implicam ou não argumentações para justificar as propostas e eleições legais. Além disso, reafirmamos a disparidade entre as demandas e respostas e a própria compreensão Que os sujeitos profissionais terão disso. Porém, isso não significa Que possamos refutar um entrelaçamento entre as demandas práticas e as transformações tecnológicas, o aparato normativo que buscará sustentá-las e a forma como o sujeito se relacionará com uma e outra. Por fim, para transpormos essa primeira etapa de possibilidade ética, lembramos que a idéia de 
Que a moral pode ser uma estrutura muito forte de existências sem estar ligada, unicamente, a um sistema autoritário, nem jurídico em si, nem a uma estrutura de disciplina, fascina Foucault ${ }^{(3)}$. Essas considerações são importantes para pensar o trabalho na enfermagem, pois ali onde parece nada existir, além de regra e disciplina, é justamente onde pode estar o maior potencial de resistência e recriação.

\section{Possibilidade Ética II: o valor dado à conduta e ao conhecimento}

Disposição e bom humor são ótimos aliados para tornar menos pesado o dia-a-dia dentro de um ambiente com tanto sofrimento. Além disso, respeito mútuo e trabalho em equipe tornam o trabalhar menos árduo. Uma equipe competente envolve os aspectos anteriormente citados, somados ao conhecimento técnico; e, Quando no final do turno, você passa o plantão com a sensação de ter concretizado todo o processo de enfermagem e outros objetivos pontuados no início da jornada, com Qualidade e reconhecimento. Mas, a recompensa, também, se faz presente na alta, principalmente Quando se consegue uma interação/afeto entre equipe/paciente/familiar. (Sujeito 9)

Logo Que entrei na UTI, não tinha nada de prática com ventilação mecânica; Quando o paciente era intubado, eu precisava arrumar o ventilador. Isso foi uma das causas por eu ter ido fazer especialização em UTI; eu precisava saber para poder fazer corretamente. (Sujeito 16)

As falas acima reforçam o valor dado ao conhecimento no contexto da UTI. No entanto, elas não trasmitem um viés de Que a conduta seja relegada em detrimento do conhecimento considerado como competente. Na verdade, essas falas mostram uma articulação possível entre constituir-se como sujeito de conduta na UTI e, por isso, constituir-se como sujeito do conhecimento. Logo, nessa etapa, centramos a análise no valor dado à conduta e/ou ao conhecimento; na próxima etapa (Possibilidade Ética III: da governabilidade de si no confronto com a técnica), processamos a Questão da produção do conhecimento 'necessário' à prática do cuidado do sujeito na UTI.

Encontramos artigos Que reforçam a máxima constituir-se em sujeito de conduta e, ao mesmo tempo, constituir-se como sujeito do conhecimento. Conhecimento que é entendido como a busca da instrumentalização - não só técnica, mas política - Que pode levar a uma compreensão crescente do contexto em Que se vive e de possíveis intervenções a serem forjadas ${ }^{(1)}$; sujeito de conduta Que é influenciado por suas vivências, valores éticos e pessoais e pela capacidade de estabelecer um relacionamento terapêutico e consciente da complexidade Que envolve o ser humano ${ }^{(12)}$. Detectamos, também, nas fontes documentais: lamento à prioridade, dos/as enfermeiros/as intensivistas, às necessidades psicobiológicas em detrimento das necessidades psicossociais e psicoespirituais ${ }^{(12)}$; aprovação do atrelamento da competência à detenção de conhecimentos científicos para embasar as discussões e ações do fazer profissional ${ }^{(13)}$; preocupação com a dicotomia dimensão técnica/dimensão ética, no discurso e na prática dos enfermeiros ${ }^{(14)}$.

Detendo-nos no assunto da relação dicotômica dimensão técnica/dimensão ética, o artigo $^{(14)}$ Que a anuncia a exemplifica através de um fato detectado em sua respectiva investigação, ou seja, conta Que um paciente teve uma lipotímia e a enfermeira saiu correndo para chamar o médico, deixando a auxiliar atendendo a urgência, Quando era da sua competência técnica desenvolvê-lo. lá, outro artigo ${ }^{(15)}$, de certo modo, 'amplia' essa discussão, ao analisar o par sujeito técnico/sujeito ético no cotidiano das enfermeiras. Entre outros aspectos, os autores reportam-se à situação do paciente Que sofreu uma lipotímia momentânea e a respectiva ação da enfermeira. No entanto, problematizam a concepção do artigo anterior, pois naquele é referido Que a postura adotada pela enfermeira aponta para um padrão moral Que valoriza o princípio de neutralidade, isso é, de assumir uma atitude de omissão ou de afastamento do atendimento ao paciente, explicada pelo sentimento do medo e da proteção de si mesma e/ou pelo fato de não possuir a competência técnica que o momento requeria. Sendo assim, o artigo Que problematiza argumenta Que seria um equívoco dizer que a enfermeira não possuía uma referência moral no princípio da responsabilidade, tanto é Que ela procurou uma solução para o problema através da execução de uma ação Que, aparentemente, traria o resultado esperado: ela sai para chamar o médico. Logo, na compreensão deste $\operatorname{artigo~}^{(15)}$, pode-se até expressar Que faltou competência técnica para a enfermeira, mas de modo algum faltou competência ética. Prosseguem sua análise sinalizando Que mesmo Que o espetáculo oferecido pela ação tenha sido racionalizado pelo espectador, no caso particular, as auxiliares de enfermagem, como falta de conhecimento teórico, de habilidade técnica ou falta de comprometimento ético da enfermeira para com o paciente e a equipe, na verdade, o que faltou à enfermeira foi justamente a reflexão sobre a sua própria ação. Terminam asseverando Que nem sempre é uma tarefa fácil encontrar respostas para o questionamento de como e por Que isso acontece ${ }^{(15)}$.

Por sua vez, outro artigo ${ }^{(16)}$ evidencia o privilégio da competência técnica na terapia intensiva. Nessa direção, o saber estabelece a hierarquia na UTI, onde se dá mais crédito ao enfermeiro que detém o saber do Que ao Que, oficialmente, é o chefe. Nesse contexto, o enfermeiro que detém o saber é respeitado e procurado pelos antigos e pelos novos membros, Que logo se dão conta de que é por meio dele Que poderão mais facilmente entrar para o mundo dos intensivistas.

Conhecimento técnico e político versus conduta, dimensão técnica versus dimensão ética, necessidades psicobiológicas versus necessidades psicossociais e psicoespirituais, tensões que constituem, sim, uma subjetividade interessada. Portanto, balizadas na assertiva, referida acima, de Que encontrar respostas para o Questionamento de como e por Que isso acontece nem sempre é uma tarefa fácil(16), explicitamos Que enfermeiras/os têm desenvolvido habilidades para funcionar em diferentes ambientes, por vezes, nada 'regulados', nada 'perfeitos', utilizando modelos nada 'uniformes'. Inclusive, artigo ${ }^{(17)}$ lembra o cientista social Daniel Chambliss, para validar a noção de Que os problemas na enfermagem são estruturais e não intelectuais.

E, como a prerrogativa da autonomia, o cuidado de si, está na pauta da discussão, lembremos o dito anteriormente, ou seja, para ser artífice do próprio ethos, deve-se introduzir uma experiência, já sempre sustentada por seu próprio acontecimento histórico. Assim, de certa maneira, na contramão de um discurso de senso comum Que veicularia a noção das/os enfermeiras/os 'simplesmente' priorizarem a conduta em detrimento do conhecimento técnico e político, ou de sustentarem a dicotomia dimensão ética/dimensão técnica, ao utilizarmos a expressão subjetividade interessada, reportamo-nos a um estudo(18) para tentar ancorar nossas reflexões. 
Nesse estudo ${ }^{(18)}$, primeiro, são sinalizadas as condições da instituição hospitalar da segunda metade do século XIX, onde a figura do médico já estava introjetada, aí ocupando um espaço privilegiado como detentor de um saber científico, otimizado pelas invenções de diversos aparelhos que auxiliam no diagnóstico e tratamento de doenças. Após esse primeiro destaque, é analisado, então, o modo de introjeção da enfermagem nesse contexto de possibilidade, ou seja, é avaliado que o fato da enfermeira executar um papel determinado na instituição hospitalar daquela época justificar-se-ia pelo ínfimo espaço para desenvolver Qualquer saber, na medida em Que o cuidado de enfermagem não era a maior preocupação e sim a disciplina daQueles Que prestavam os cuidados. Assim, a disciplina tinha a função de sustentar o próprio hospital como um espaço de cura. Nesse sentido, a autora pensa Que o fato da enfermeira estar vinculada ao trabalho médico permitiu que esta "usufruísse seu prestígio, já que, naQuela época, havia no hospital muitos cuidadores Que não tinham um reconhecimento profissional. Florence Nightingale, preocupada em organizar uma profissão, vinculou-a a um saber Que tinha status, um saber próximo da ciência"(18).

Enfim, nessa perspectiva, pensamos Que uma subordinação da enfermeira ao médico, uma ênfase à disciplina em detrimento de um saber e todas as possíveis tensões, inclusive já descritas anteriormente, facultaria, em determinado tempo e contexto, realocá-la na ordem de uma subjetividade interessada, na ordem de um cuidado de si. Tanto seria possível Que o mesmo estudo ${ }^{(18)}$ considera Que os desenvolvimentos profissionais posteriores da enfermagem, também, representados pelo ingresso na Universidade e pela preocupação em construir um saber próprio, fazem circular "outro discurso sobre a profissão, a saber, a enfermagem como profissão autônoma e participante, em igualdade de condições com os demais profissionais da saúde"(18).

$\mathrm{E}$, mesmo Que a enfermeira fale de uma UTI locada em um serviço público, Que a viabiliza expressar o que diz a seguir, ela não deixa de perpassar as argumentações acima, isso é, a idéia de profissão autônoma e participante, em igualdade de condições com os profissionais da saúde.

Atuo há muitos anos num hospital público onde temos estabilidade de emprego e estamos categorizadas em nível hierárquico, do ponto de vista salarial e locação, no mesmo nível dos demais profissionais de nível superior, os técnicos científicos. Este pode ser um ponto de tranquilidade em se falando de stress para o profissional em comparação com os demais colegas das empresas privadas nos dias atuais. Tomar atitudes, posicionamentos com maior liberdade e que possamos ter mais autonomia e, claro, maior responsabilidade em um grande número de situações. (Sujeito I)

Dito isso, concentrar-nos-emos, agora, na ordem de outro discurso, não menos introjetado na enfermagem, não menos importante: a Questão da produção do conhecimento 'necessário' à prática do cuidado do sujeito na UTI.

\section{Possibilidade Ética III: da governabilidade de si no confronto com a técnica}

Iniciamos esta etapa a partir de outro artigo ${ }^{(19)}$, no mesmo ponto em Que se descrevia um modelo hospitalar, no Qual os cuidados médicos eram os únicos válidos por serem científicos, originandose um distanciamento entre o nível dos cuidados de enfermagem. Um local, onde os cuidados de enfermagem eram percebidos como secundários, sem importância mais significativa ou valor científico ou, mesmo, econômico. A assistência de enfermagem se resumia em dar o remédio na hora certa, cuidar do asseio, dar alimentação, fazer companhia e auxiliar o paciente na ocasião das necessidades e de um possível banho, limpar o Quarto, dar destino aos dejetos dos pacientes e cuidar dos mortos, além de ser subsidiada pelo trabalho e pensamento médico. Mas, e atualmente? Para o/a enfermeiro/a, responsável pela equipe de enfermagem e pelo cuidado, as habilidades em realizar uma observação minuciosa passam a ser cada vez mais necessárias, não apenas para simplesmente descrever os fatos ocorridos fielmente ao médico, como era preconizado por Florence Nightingale. Tais habilidades, associadas às demais habilidades técnicas e ao acervo de conhecimento em saúde, constituem patrimônio técnico-científico atual da enfermagem. Em seu agir, tem de observar e criticar a eficiência dos métodos e técnicas Que utiliza. Logo, lança mão de conhecimentos e procedimentos teoricamente organizados, sistematizados e sempre reformulados para a melhor ação ${ }^{(19)}$.

Prosseguimos esta etapa apontando alguns enunciados extraídos dos artigos. Um deles ${ }^{(1)}$ assevera Que a autodesvalorização de nosso trabalho leva-nos a desconsiderar que se pode cuidar sem tratar, mas não se pode tratar sem cuidar. Outro(13) ${ }^{(13)}$ clui Que a enfermagem está organizada como profissão institucionalizada e reconhecida por lei, dona de seu saber e sua prática definidos na teoria, mas ainda a sociedade a considera como cumpridora das ordens médicas prescritas. Um terceiro ${ }^{(20)}$ indaga por Que os enfermeiros, frequentemente, relegam o seu saber e fazer específico e privativo, cuja aplicação provocaria ou aceleraria o desenvolvimento científico da profissão, em detrimento de fazeres dependentes, os Quais poderiam ser delegados a outros profissionais da equipe de enfermagem ou seQuer ser assumidos pela enfermagem. $\mathrm{O}$ Quarto artigo pesQuisado ${ }^{(21)}$, ao abordar enfermeiros assistenciais responsáveis pelo cuidado de enfermagem a pacientes com necessidades de assistência intensiva, semi-intensiva, cuidados intermediários e mínimos, extrai uma divisão enfermeiro - trabalho intelectual/técnico de enfermagem - trabalho manual, Que acarreta conflitos internos, reflete-se negativamente na assistência prestada ao paciente e interfere na autonomia do profissional enfermeiro, uma vez Que, frequentemente, o afasta de sua ação cuidadora direta, minimizando o seu potencial de ação nesse processo. Por último, uma das enfermeiras entrevistadas narra a sua história de prática na UTI:

Trabalhar em um CTI de um hospital no Qual temos possibilidade de gerir nosso próprio negócio e que o aumento efetivo de número de profissionais ocorreu pela aproximação do cuidado ao paciente faz o meu dia-a-dia como enfermeira intensivista gratificante. Quero dizer com isto Que, neste hospital, a enfermagem pode e deve fazer a sua parte com competência e isto repercute tanto na Qualidade da assistência ao paciente, Quanto na ampliação do nosso reconhecimento nesta mesma instituição e na comunidade. (Sujeito 13)

A fala dessa enfermeira e os artigos são discursos que se articulam, sobrepõem-se e, em determinados vieses, diferem-se. 
$\mathrm{Na}$ verdade, o dito dessa enfermeira contemporiza os enunciados dos respectivos artigos. De certo modo, ela responde à indagação: Quem somos nós, enfermeiras, profissionais de saúde, neste momento da história?(1) Para tanto, ela informa de uma enfermeira intensivista Que necessitou ressignificar o cuidado de enfermagem em um ambiente permeado pela tecnobiomedicina. Lá, na UTI, onde dar banho, fazer higiene oral, alimentar, alternar decúbito, aplicar medicamentos, entre vários e vários outros cuidados de enfermagem até mais complexos do Que esses, assumem na contemporaneidade uma dimensão nunca experimentada pela enfermagem. Ou seja, nem precisamos avançar para cuidados mais complexos (como ventilação mecânica, balão intra-aórtico, hemodiálise, entre inúmeros), fieuemos naQueles considerados, já lá no século XIX, secundários e menos significativos e perguntemos: no contexto da terapia intensiva, é possível ainda considerá-los menores do Que o tratamento do paciente? E não estamos nem abordando a Questão do conhecimento científico e a construção de toda uma expertise da enfermagem. Tratamos, especificamente, da ordem mesma daquele cuidado insignificante, daQuele que hoje interfere diretamente, Quando não realizado ou indevidamente operacionalizado, na gravidade dos pacientes, nas complicações destes mesmos pacientes, no seu tempo de internação na UTI e, até mesmo, na sua evolução para o óbito.

Além disso, a enfermeira fala em gerir nosso próprio negócio, e Que o aumento efetivo de profissionais deu-se pela aproximação desse tipo de profissional do cuidado ao paciente. Ela nos fala, pois, de um privilégio político e social. Mas, esse mesmo cuidado tem sido ressignificado, também, por Que este interfere diretamente no econômico. É ilusório dizermos hoje Que cuidado não gera lucro para a instituição hospitalar; aliás, se indevidamente administrado, gera um grande prejuízo. Em suma, ela nos diz que devemos nos ocupar com nós mesmos de outro modo. Mostrar-se, assim, como enfermeira seria assumir as práticas dos cuidados e não delegar para os demais profissionais; paradoxalmente, Quando confiamos "o nosso negócio" aos demais, deixamos de nos mostrar (de cuidar de nós) e passamos a fazer coisas dos outros.

\section{CONSIDERAÇÕES FINAIS}

Quem seremos nós, enfermeiras/os, profissionais de saúde, no próximo momento da história? Como cuidaremos de nós? Replicamos essa indagação, buscando reforçar o caráter histórico e contingente das nossas ações. Desse modo, as ações desenvolvidas em cada momento da nossa história encontraram suas condições de possibilidade dentro de certas epistémes e de certos espaços de saber e poder. Portanto, o próximo acontecimento histórico é muito mais da ordem da experiência do Que das condições transcendentais e dos fundamentos. Assim, é preciso dizer Que o cuidado de si deve tomar forma a partir de diferentes combinações, mas sempre num pertencimento a um grupo. Lembremos, pois, "somente no interior do grupo e na distinção do grupo, pode o cuidado de si ser praticado"(3).

Nessa exata direção, desafiamos os possíveis leitores deste artigo a experimentarem inverter a ordem das possibilidades éticas I, II e III. Mas, antes mesmo de efetivar esse exercício, sinalizamos Que não estamos negando o caráter disciplinar da Lei, a ênfase dada à conduta em detrimento do conhecimento, e, até mesmo, por que não pensar nisto também, um atrelamento 'privilegiado' e interessado do/a enfermeiro/a ao arsenal da tecnobiomedicina no contexto da terapia intensiva; nem Queremos "botar para baixo do tapete" a noção do governo de si como capaz de induzir os sujeitos a cuidarem de si, a fazerem suas escolhas e sobre o Que pautarem os seus valores; por fim, de modo algum pretendemos prescrever uma noção de autonomia 'ideal' da profissão. Assim, ler essas possibilidades éticas na ordem inversa objetiva demonstrar Que, mais do Que nunca, experimentamos um atual momento histórico, sob a confluência dessas três possibilidades éticas.

Por sua vez, o nosso desafio, na escrita deste texto, consistiu em olhar sob outro ângulo o dito nos escritos dos artigos, o expresso pelos/as enfermeiros/as intensivistas, procurando efetivar a potencialidade autônoma de cada uma dessas possibilidades éticas. Nesta direção, em primeiro, nós vimos o cuidado de si manifestarse, organizar-se e difundir-se em um grupo muito mais político do Que preocupado em conhecer a 'sua' identidade profissional, enfrentando, sempre, a tarefa de construir alternativas mais satisfatórias para a sua prática profissional. Por este outro ângulo, pudemos fazer uma narrativa, mesmo Que sempre parcial e provisória, de uma existência que foi muito mais modelada por nós do Que normalmente costumamos acreditar. Mas, enfatizamos, não se trata de uma produção individual e alheia a QualQuer vínculo com os outros; pelo contrário, ao narrar nossa história, ingressamos em uma trama mais ampla Que nos contém e nos molda já não mais como atores principais do relato, sim como expectadores, devendo incluir os outros em sua própria história, devendo ao mesmo tempo viver e contar ${ }^{(21)}$.

\section{REFERÊNCIAS}

1. Lunardi VL. Ampliando a compreensão do conceito de autonomía. Texto Contexto Enferm 1997; 6(3): 304-13.

2. Hermann N. Ética e estética. A relação Quase esquecida. Porto Alegre: EDIPUCRS; 2005.

3. Foucault M. A hermenêutica do sujeito. $2^{\text {a }}$ ed. São Paulo: Martins Fontes; 2006.

4. Santiago, MMA; Palácios, M. Temas éticos e bioéticos Que inquietaram a Enfermagem: publicações da REBEn de 19702000. Rev Bras Enferm 2006; 59(3): 349-53.

5. Foucault M. História da Sexualidade 2. O uso dos prazeres. $8^{\mathrm{a}}$ ed. Rio de Janeiro: Edições Graal; 1998.
6. Lunardi VL. Uma crítica da moral da obediência para a busca de uma moral autônoma da enfermeira. Texto Contexto Enferm 1995; 4(2): 73-92.

7. Oguisso T. História da legislação do exercício da enfermagem no Brasil. Rev Bras Enferm 200 I; 54(2): 197-207.

8. Lorenzetti I. A “nova” lei do exercício profissional da enfermagem: uma análise crítica. Rev Bras Enferm 1987; 40(2 e 3): 167-76.

9. Passos ES. A ética na enfermagem. Rev Bras Enferm 1995; 48(1): 85-92.

10. Passos ES. Tendências da ética profissional na modernidade. 
Rev Bras Enferm 1993; 46(1): 56-62.

11. Wendhausen ALP, Rivera S. O cuidado de si como principio ético do trabalho em enfermagem. Texto Contexto Enferm2005; 14(1): 1 I I-9.

12. Espírito Santo TIM. Segurança emocional como necessidade humana básica - atuação do enfermeiro junto ao cliente em unidade de terapia intensiva. Rev Bras Enferm 1985; 38(3 e 4):231-37.

13. Martins MAF, Guerra DR, Guedes MVC. Libertas Que serás enfermagem. Rev Bras Enferm 1998; 5 I (4): 51 1-22.

14. Germano RM, Brito RS, Teodósio SS. O comportamento ético dos enfermeiros dos hospitais universitarios. Rev Bras Enferm 1998; 51(3): 369-78.

15. Oliveira MLC, Guilhem D. O agir ético na prática profissional cotidiana das enfermeiras. Rev Bras Enferm 2001; 54(I): 63-73.
16. Bastos MAR. O saber e a tecnología: mitos de um centro de tratamento intensivo. Rev Latino-am Enferm 2002; 10(2): 13 1-6.

17. Nelson S. Conhecimento incorporado? A constituíção da expertise como prática moral na enfermagem. Texto Contexto Enferm 2007; 16(1): 136-41.

18. Kruse MHL. Os poderes dos corpos frios. Das coisas que se ensinam às enfermeiras. Brasília (DF): ABEn; 2004.

19. Andrade AC. A enfermagem não é mais uma profissão submissa. Rev Bras Enferm 2007; 60(16): 96-8.

20. Lunardi VL, Lunardi Filho WD, Silveira RS, Soares NV, Lipinski JM. O cuidado de si como condição para o cuidado dos outros na prática de saúde. Rev Latino-am Enferm 2004; 12(6): 933-9.

21. Bueno FMG, Queiroz MS. O enfermeiro e a construção da autonomía profissional no processo de cuidar. Rev Bras Enferm 2006; 59(2): 222-7. 